\title{
Vibration-based Condition Monitoring of Heavy Duty Machine Driveline Parts: Torque Converter, Gearbox, Axles and Bearings
}

\author{
Källström Elisabeth ${ }^{1,5}$, Lindström John ${ }^{2}$, Håkansson Lars ${ }^{4}$, Karlberg Magnus ${ }^{1}$, Lin Jing ${ }^{3}$ \\ ${ }^{1}$ Department of Engineering Sciences and Mathematics, Luleå University of Technology, Luleå, Sweden \\ Magnus.Karlberg@ltu.se \\ 2 ProcessIT Innovations, Luleå University of Technology, Luleå, Sweden \\ john.lindstrom@ltu.se \\ ${ }^{3}$ Department of Civil, Environmental and Natural Resources Engineering, Luleå University of Technology, Luleå, Sweden \\ janet.lin@ltu.se \\ ${ }^{4}$ Department of Mechanical Engineering, Linnaeus University, Växjö, Sweden \\ Lars.Hakansson@lnu.se \\ 5 Volvo Construction Equipment, Eskilstuna, Sweden \\ elisabeth.kallstrom@volvo.com
}

\begin{abstract}
As more features are added to the heavy duty construction equipment, its complexity increases and early fault detection of certain components becomes more challenging due to too many fault codes generated when a failure occurs. Hence, there is a need to complement the present onboard diagnostics method with a more reliable diagnostics method for adequate condition monitoring of the heavy duty construction equipment in order to improve uptime. Major components of the driveline (such as the gearbox, torque converter, bearings and axles) are components necessary to monitor. A failure among any of these major components of the driveline may result in the machine standing still until a repair is scheduled.

In this paper, vibration based condition monitoring methods are presented with the purpose to provide a diagnostic framework possible to implement onboard for monitoring of critical driveline parts in order to reduce service cost and improve uptime. For the development of this diagnostic framework, sensor data from the gearbox, torque converter, bearings and axles are considered. Further, the feature extraction

\footnotetext{
Källström Elisabeth et al. This is an open-access article distributed under the terms of the Creative Commons Attribution 3.0 United States License, which permits unrestricted use, distribution, and reproduction in any medium, provided the original author and source are credited.
}

of the data collected has been carried out using adequate signal processing methods, which includes: Adaptive Line Enhancer and Order Power Spectrum respectively. In addition, Bayesian learning was utilized for adaptive learning of the extracted features for deviation detection. Bayesian learning is a powerful prediction method as it combines the prior information with knowledge measured to make updates. The results indicate that the vibration properties of the gearbox, torque converter, bearings and axle are relevant for early fault detection of the driveline. Furthermore, vibration provides information about the internal features of these components for detecting deviations from normal behavior.

In this way, the developed methods may be implemented onboard for the continuous monitoring of these critical driveline parts of the heavy duty construction equipment. Thus, if their health starts to degrade a service and/or repair may be scheduled well in advance of a potential failure and in that way the downtime of a machine may be reduced and costly replacements and repairs avoided.

\section{INTRODUCTION}

Being a competitive business, the construction equipment business tries to find new ways to increase customer satisfac- 
tion. An important way to achieve this is by reducing unwanted stops due to failure of critical mechanical components of the driveline, for instance the gearbox, the torque converter, the bearings and the axles. In the last decade, monitoring of machinery with changing rotational speed has attracted a lot of research contributions. This section comprises a review of some of the previous research carried out with focus on the Gearbox, Bearings, Axles and the Torque Converter. In Fig. 1, the Wheel Loader and its driveline parts is illustrated. Randall (Randall, 2004a), discussed how dif-

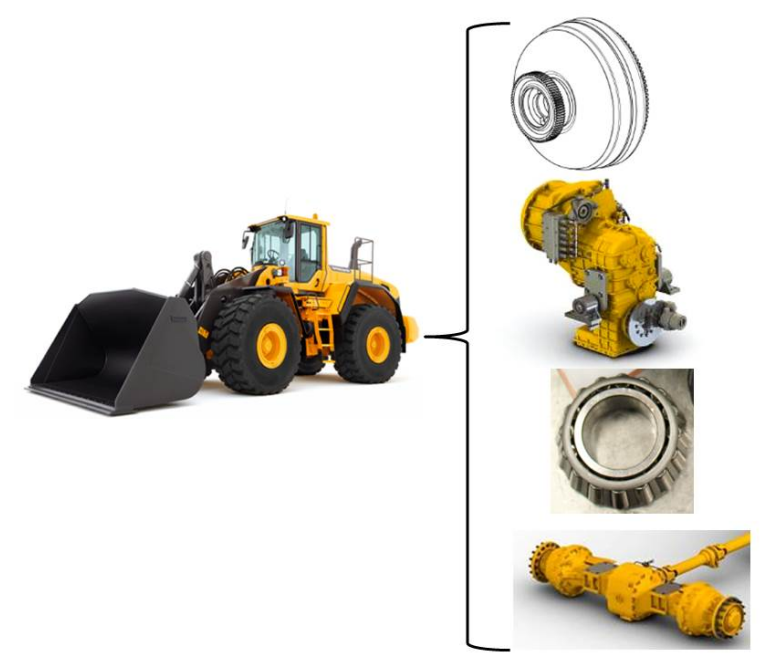

Figure 1. The Wheel Loader and its Driveline Parts

ferent faults (shaft speed faults, electric machine faults, gear faults, bearing faults and reciprocating machine faults) reveal themselves in the vibration signature. Randall explained that the signal produced by gear is deterministic and also gear wear are often noticed at the gear meshing frequency and its harmonics. Furthermore, gear wear are usually first seen as an increase on the second harmonic of tooth meshing frequency, whereas localized faults are seen at other harmonics of the rotational speeds for the gear on which they are located (Randall, 2004a). Further, Randall added that localized faults such as cracks and spalls tend to give a wide range of harmonics and sidebands throughout the spectrum, while slow changing faults give stronger harmonics grouped around zero frequency and as sidebands around the harmonics of tooth mesh frequency (Randall, 2004a). Randall (Randall, 2004b) further discussed different analysis techniques that have been proposed for diagnosing faults in rotating machinery, such as synchronous averaging, order tracking, adaptive noise cancellation, demodulation and envelope analysis. Fan et al. (Fan \& Zuo, 2006), proposed the use of Hilbert Transform (HT) and Wavelet Packet Transform (WPT), an Envelope time-frequency approach for the detection of gear faults. They stated that WPT provided better frequency resolution in the higher frequency region than the traditional Wavelet
Transform (Fan \& Zuo, 2006). However, because the vibration signal is not synchronized with the rotational speed of the shaft, this may not be a suitable approach for a gearbox with changing rotational speed due to spectral smearing caused by speed fluctuation (Li \& Ai, 2008). Li et al. (Li \& $\mathrm{Ai}, 2008)$, introduced and applied the Order Bi-Cepstrum to gearbox fault diagnosis, a combination of order analysis and bi-cepstrum technique. Even though, the order bi-ceptrum revealed the bearing inner race fault, lots of other relevant information were lost (Li \& Ai, 2008). Sawalhi et al. (Sawalhi $\&$ Randall, 2008), presented a simulation model for a timevarying gearbox test rig that allows different types of faults to be implemented. They did this by modeling a complete system of gears and shafts supported with time-varying, nonlinear stiffness bearing model (Sawalhi \& Randall, 2008). Furthermore, having compared the simulated faults with experimental localized fault signals using spectral comparisons, Spectral Kurtosis (SK) and Envelope analysis where both signals gave similar results, they concluded that simulation models will be useful for producing fault signals from gearboxes for testing new diagnostic algorithms (Sawalhi \& Randall, 2008). He et al. (He \& Li, 2011), presented a gearbox fault detection method where they first filtered out periodic signal using an adaptive narrow-band interference cancellation filter. They claimed that the gear periodic signal was an interference signal to the impulse signal of the damaged gear $(\mathrm{He}$ \& Li, 2011). However, since gear signals are periodic, filtering out the periodic component removes the information about which gear is damaged and thus information about gear fault may be lost (Brandt, 2011; Randall, n.d.; Ho \& Randall, 1997). Furthermore, bearing faults are stochastic and may be extracted after removal of periodic component from the vibration signal but not gear faults (Ho \& Randall, 1997; Randall \& Antoni, 2011). Hong et al. (Hong \& Dhupia, 2014), combined the Fast Dynamic Time Warping (Fast DTW) and Correlated Kurtosis (CK) techniques for time domain monitoring of localized gear faults. Fast DTW extracts the periodic impulse excitation caused by the faulty gear tooth and then the extracted signal is resampled for further diagnostic analysis using CK (Hong \& Dhupia, 2014). Furthermore, CK identifies the local gear by taking advantage of the peridicity of the gear faults. Further, this approach showed the degradation level of the gear mesh stiffness (Hong \& Dhupia, 2014). Guo et al. (Guo, Wu, Na, \& Fung, 2016), proposed an envelope synchronous average scheme for multi-axis gear faults detection using fast kurtogram algorithm. Thereafter, the extracted envelope signal was resampled to the order domain synchronously averaged to both avoid spectral smearing and remove random components (Guo et al., 2016).

Immovili et al. (Immovilli, Bellini, Rubini, \& C., 2010) compared the capability of using electric current and vibration signals for bearing fault detection in induction machines. They concluded that vibration signals are a robust indicator for de- 
tecting faults in a bearing provided a suitable signal analysis method is utilized (Immovilli et al., 2010). Abdusslam et al. (Abdusslam, Gu, \& Ball, 2009) analyzed vibration data for bearing fault detection via a simple bearing test rig using Fast Fourier Transform (FFT) of the signal and an envelop analysis of the signal. Further, the bearing test rig comprised of a 3phase electrical induction motor, a dynamic break, four shafts connected by three flexible couplings, two bearing housings and an amplifier (Abdusslam et al., 2009). They concluded that the envelope analysis was more reliable in revealing the faults (Abdusslam et al., 2009). Randall et al. (Randall \& Antoni, 2011) stated that bearing frequency components are cyclostationary due to random slip which is dependent on the ratio of the axial load to the radial load. After a review of different techniques, they recommended the envelope spectrum for bearing fault detection. Brkovic et al. (Brkovic et al., 2017) utilized the wavelet transform for ball bearing feature extraction. They carried out this study using a simple experiment setup which involved installing a ball bearing in a motor driven mechanical system (Brkovic et al., 2017). The setup comprised of a three-phase induction motor connected to a dynamometer and a torque sensor, and an accelerometer attached to the motor housing (Brkovic et al., 2017).

Huibin et al. (Huibin, Mengxi, Chengxia, \& Bo, 2012) performed an experimental study concerning noise identification of the rear driving axle using theories and methods for acoustic array measurements. They observed that the dominating frequencies in the measured signal are related to the gear meshing vibration (Huibin et al., 2012). Shao et al. (Shao, Liang, Gu, Chen, \& Ball, 2011) proposed a Radial and Basis Function (RBF) and Back Propagation (BP) neural networks as a fault and diagnosis procedure for rear axle gear utilizing Root Mean Square (RMS) and Kurtosis features of the measured vibration signals. Santacruz et al. (Santacruz \& Félix, 2014) described an optimization process for realtime vibration and frequency monitoring system on a differential axle fixed rig using a field-programmable gate array (FPGA), an online analysis data storage unit which located the strongest frequency components by computing frequency spectrum. In addition to the FPGA, an offline program which calculated the RMS and variance of the vibration in time domain and computation of an histogram from the series with the strongest frequency component was also utilized (Santacruz \& Félix, 2014). They reached the conclusion that the execution of the test under a controlled platform yielded acceptable performance with the axle shaft having the most intense vibration based on the RMS value. However, they stated that the methods needs to be further validated (Santacruz \& Félix, 2014).

Although, a lot of research has been conducted in the area of condition monitoring of rotating machinery, an onboard vibration based monitoring for Heavy duty construction equipment major driveline parts (such as the torque converter, bear- ings, gearbox and axles) seems to have been overlooked. In this paper, an onboard vibration-based monitoring approach is presented for the monitoring of major components of the driveline in an heavy duty construction to enable early fault detection. An Adaptive Line Enhancer (ALE) filter which is steered with a Recursive-Least-Squares (RLS) algorithm was utilized to separate the deterministic and stochastic vibration signals before further signal analysis is performed using the Order Power Spectrum and Bayesian Learning. The RLS can adapt to changing input statistics and converges faster (Haykin, 2014). On the other hand, the Bayesian Learning approach gives a narrower confidence interval bound since it utilizes prior knowledge and measured knowledge (Hamada, Wilson, Reese, \& Martz, 2008; Gelman et al., 2014). In addition, the presented method is robust and easy to implement. To summarize, the approach presented in this paper will improve uptime, increase customer satisfaction, reduce warranty cost and generate money for the company as this can be sold as an added feature.

\section{Materials AND Methods}

\subsection{Experimental Setup}

A Volvo Construction Equipment L180H Wheel Loader was used in the experiments. The machine was warmed-up before the test cycles and the bucket was loaded with 8 tonnes of gravel. The Volvo CE test track in Eskilstuna, Sweden, was used in the experiments as driving track, using one driver and similar driving style in all measurements. The measured parameters used in the investigation are the engine speed and the torque converter vibration. The experiment was controlled and an adequate number of recordings were made.

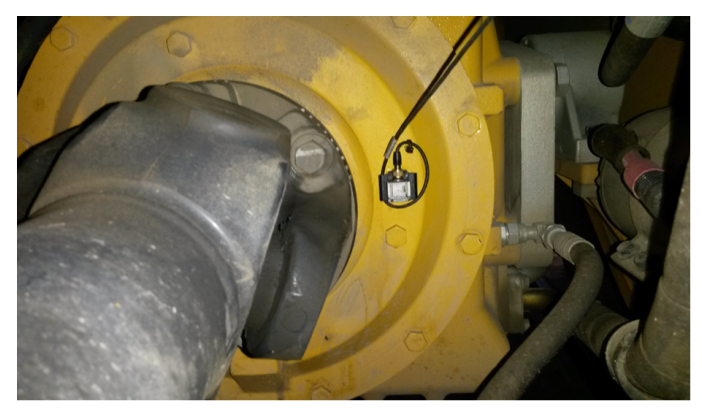

Figure 2. L180H Wheel Loader with accelerometer attached close to the Output Shaft of automatic transmission housing.

\subsection{Measurement Equipment and Setup}

The vibration signals were recorded using a LMS Scadas SCR05 Data Acquisition system, sampling frequency $6400 \mathrm{~Hz}$, 
connected to a triaxial accelerometers attached on the top side of the torque converter housing as in Figure 5, two triaxial accelerometers attached around the structure around the pinion of the rear and front axle as in Figures 3 and 4 and one triaxial accelerometer attached around the output shaft from the gearbox as in Figure 2.

In order to adequately measure vibrations of the torque converter, triaxial accelerometers were mounted as close as possible to the torque converter as in Figure 5. The accelerometer on the left side of the torque converter housing was mounted using instant adhesive- Loctite 454 and the one on the top side was mounted using a magnet. The engine speed from the machine CAN-bus was logged synchronously with the vibration data.

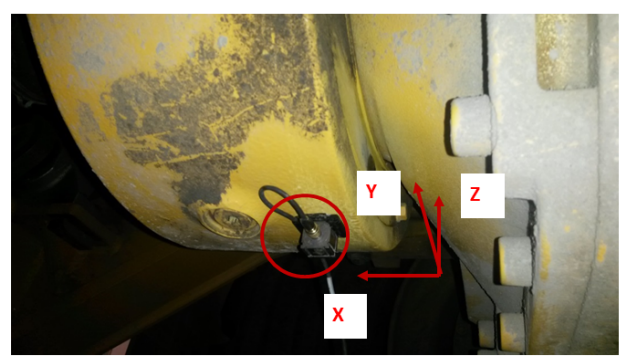

Figure 3. L180H Wheel Loader with accelerometer mounted on the structure around the pinion of the rear axle.

\subsection{Evaluation of the vibration of Driveline parts}

The vibration properties of the drive-line may be investigated with the aid of order analysis techniques, frequency domain, time-frequency domain analysis, etc. (Brandt, 2011). Order analysis techniques, usually referred to as order-tracking, are generally utilized in rotating machinery analysis where the rotational speed changes over time. Furthermore, order analysis techniques transform a non-stationary signal in the time domain into a stationary signal in an angular domain providing information about the vibration related to the changing rotational speed (Li \& Ai, 2008; Junsheng, Yu, \& Dejie, 2010).

Order analysis is carried out by first, synchronously resampling the measured vibration based on the rotational speed measured on an reference shaft (Brandt, 2011). In other words, synchronous sampling adapts the sample rate of the vibration signal with the changing rotational speed of the reference shaft, ensuring that the vibration is sampled at an equal

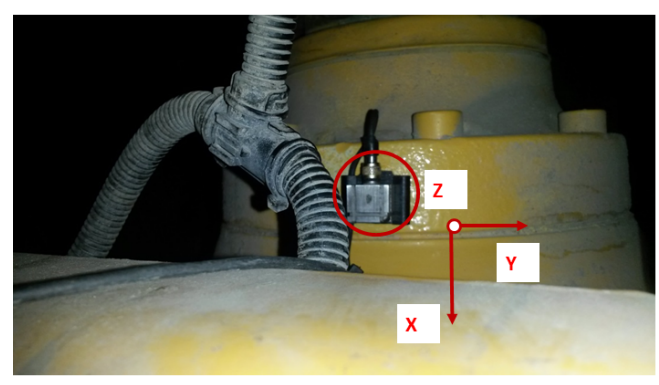

Figure 4. L180H Wheel Loader with accelerometer mounted on the structure around the pinion of the front axle.

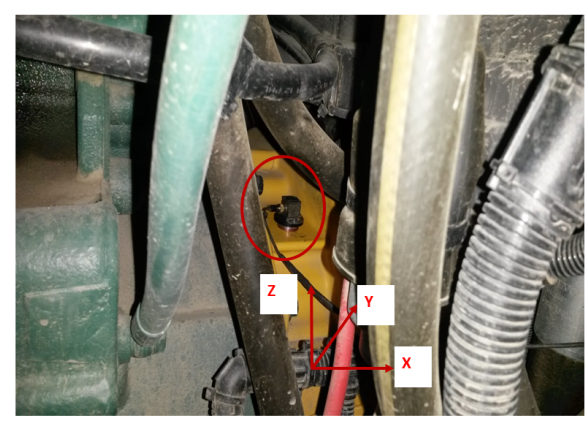

Figure 5. L180H Wheel Loader with accelerometer attached on the top side of the torque converter housing.

angle increment (Junsheng et al., 2010). Furthermore, the order analysis technique transforms a signals non-stationary components whose vibration frequencies are related to the rotation speed in the time domain into stationary signal components in the angular domain and thus provides information about the vibration components related to the changing rotational speed (Junsheng et al., 2010). In addition, this prevents spectral smearing (Li \& Ai, 2008). The synchronously resampled samples of the vibration data are said to be in the order or angle domain (Brandt, 2011). Thus, the synchronous sampled vibration originating from rotating parts will basically have a fixed number of samples per cycle and this number is related to the rotational speed measure of the shaft. Synchronously resampled signals may be analyzed using different signal processing techniques.

In this paper, an Adaptive Line Enhancer (ALE) filter which 
is steered with a Recursive-Least-Squares (RLS) algorithm was utilized to make this separation before further signal analysis was performed using the Order Power Spectrum and Bayesian Learning. Fig. 6 shows the vibration-based condition monitoring framework presented in this paper.

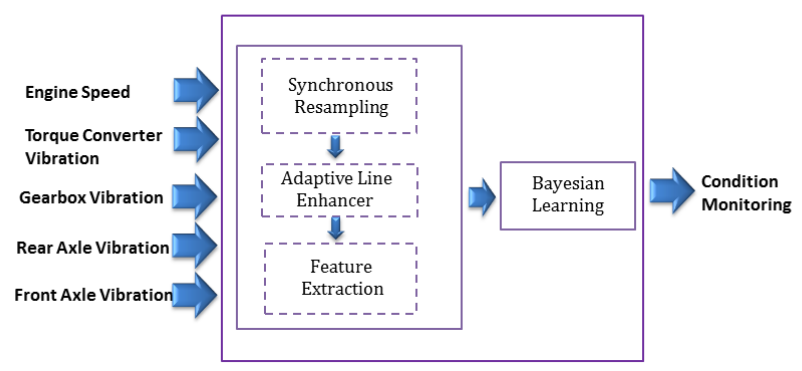

Figure 6. The proposed onboard vibration-based condition monitoring framework for transmission and axles

\subsection{Vibration Analysis of the Bearing}

The frequencies of the inner and outer race, the cage frequency and the ball/roller spin frequency reveal defects in the respective parts of a bearing and they are produced as (Randall \& Antoni, 2011; Tuma, 2014; Källstöm, Lindström, Håkansson, Karlberg, \& Öberg, 2017).

$$
\begin{gathered}
f_{\text {inner }}=\frac{n}{2} f_{\text {sh }}\left\{1+\frac{D_{\text {ball }}}{D_{\text {pitch }}} \cos \phi\right\} \\
f_{\text {outer }}=\frac{n}{2} f_{\text {sh }}\left\{1-\frac{D_{\text {ball }}}{D_{\text {pitch }}} \cos \phi\right\} \\
f_{\text {cage }}=\frac{1}{2} f_{\text {sh }}\left\{1-\frac{D_{\text {ball }}}{D_{\text {pitch }}} \cos \phi\right\} \\
f_{\text {spin }}=\frac{D_{\text {pitch }}}{2 D_{\text {ball }}}\left\{1-\left(\frac{D_{\text {ball }}}{D_{\text {pitch }}} \cos \phi\right)^{2}\right\}
\end{gathered}
$$

where $f_{\text {inner }}$ is the inner race frequency, $f_{\text {outer }}$ is the outer race frequency, $f_{\text {cage }}$ is the cage frequency, $f_{\text {spin }}$ is the ball/roller spin frequency $n$ is the number of balls/roller, $f_{s h}$ is the shaft speed, $D_{\text {ball }}$ is the ball/roller diameter, $D_{\text {pitch }}$ is the pitch circle diameter and $\phi$ is the contact angle.
It is important to note that bearings in an actual transmission exhibits stochastic behavior with low frequencies (Randall \& Antoni, 2011; Giannakis, 1999). The measured vibration data is a combination of the deterministic signal (gears, turbine, impeller, stator, etc) and the stochastic signal (Randall, Sawalhi, \& Coats, 2011).The deterministic part of the signal tends to mask the bearing signal, hence the need to separate the stochastic part from the deterministic part after the vibration signal has been synchronously resampled to the order domain (Brandt, 2011; Randall et al., 2011). An ALE steered with a RLS adaptive algorithm was utilized to make this separation before further signal analysis is performed (Widrow $\&$ Stearns, 1985; Haykin, 2014). For adequate signal separation the time delay, filter order and the convergence must be carefully selected (Widrow \& Stearns, 1985; Haykin, 2014). The delay of the ALE should be longer than the correlation length of the random part of the signal (Widrow \& Stearns, 1985; Haykin, 2014; Ho \& Randall, 1997).

\subsubsection{Adaptive Line Enhancer}

Adaptive filtering is based on a step by step adjustment of the filter coefficients during the filtering operation, allowing the tracking of slowly changing statistics of the input data (Proakis \& Manolakis, 2006; Haykin, 2014). To separate deterministic and stochastic vibration signal, an ALE may be utilized (Ho \& Randall, 1997; Widrow \& Stearns, 1985). An ALE is an adaptive self-tuning filter where the input signal is a mixture of a deterministic signal and an uncorrelated stochastic signal from one sensor (Widrow \& Stearns, 1985; Haykin, 2014; Ramli, Noor, \& Samad, 2012). Furthermore, an ALE is capable of detecting extremely low-level sine waves in noise (Widrow \& Stearns, 1985). The RLS adaptive algorithm is used in this paper to steer the ALE filter. For adequate signal separation the time delay, filter order and the convergence must be carefully selected based on the given signal (Randall et al., 2011; Ho \& Randall, 1997). The delay of the ALE filter should be longer than the correlation length of the random part of the signal (Randall et al., 2011; Ho \& Randall, 1997). The ALE is illustrated in figure 7 (Ho \& Randall, 1997; Widrow \& Stearns, 1985).

When vibration is measured on a rotating machinery, the measured vibration data is a combination of the deterministic signal (gears, turbine, impeller, stator etc.) and the stochastic signal (bearings) (Randall et al., 2011).The deterministic part of the signal tends to mask the bearing signal, hence the need to separate the stochastic part from the deterministic part after the vibration signal has been synchronously resampled to the order domain (Brandt, 2011; Randall et al., 2011).

\subsection{Power Spectrum}

When estimating spectral properties of a signal, it is important to select an appropriate scaling of the spectrum estima- 


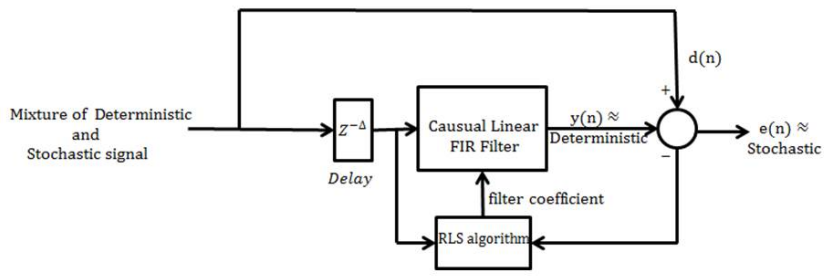

Figure 7. Adaptive Line Enhancer (ALE)

tor (Harris, 1978; Bendat \& Piersol, 2000). The spectrum estimates may be scaled for either the tonal components of a signal: Power Spectrum (PS) estimates, or the random part of a signal: Power Spectral Density (PSD) estimates (Harris, 1978).

The PS of a periodic sampled signal $x(n)$ is usually computed using the Welchś spectrum estimator

(Andren, Håkansson, Brandt, \& Claesson, 1978). The Welch spectrum estimate is obtained by averaging a number of periodograms. Each periodogram is based on segments of a time sequence $x(n)$, each segment consisting of $N$ samples (Welch, 1967). Thus, the original time sequence of data must be divided into data segments (Welch, 1967). The Welchś power spectrum estimator is given by (Welch, 1967):

$$
\begin{array}{r}
\widehat{P}_{x x}^{P S}\left(f_{k}\right)=\frac{1}{L N U_{P S}} \sum_{l=0}^{L-1}\left|\sum_{n=0}^{N-1} x_{l}(n) w(n) e^{-j 2 \pi n k / N}\right|^{2}, \\
f_{k}=\frac{k}{N} F_{s}
\end{array}
$$

where $k=0, \ldots, N / 2, L$ is the number of periodograms, $N$ is the length of the periodogram, $l$ is related to the overlapping increment (usually $0-50 \%$ of the periodogram length), $F_{s}$ the sampling frequency, $w(n)$ is a suitable window and

$$
U_{P S}=\frac{1}{N}\left(\sum_{n=0}^{N-1} w(n)\right)^{2}
$$

is the window-dependent magnitude normalisation factor.

Further, a one-sided PS contains the total power of the pe- riodic components of a signal in the frequency interval from Direct Current (DC) to half of the Nyquist rate whereas a twosided PS contains the total power of the periodic components in the frequency interval from -Nyquist rate to the Nyquist rate.

\subsection{Bayesian Learning}

Bayes' rule uses a prior belief of the evidence based on subjective probabaility to make inference and decision (Hamada et al., 2008; Gelman et al., 2014). Bayesian Learning is a powerful tool for making prediction as it combines prior information of a parameter available with knowledge measured during an experiment in order to update the belief regarding the value of the parameter producing a result with a narrower confidence bound (Hamada et al., 2008; Gelman et al., 2014). Furthermore, Bayesian Learning utilize probability density to summarize the uncertainty of the value of a parameter (Hamada et al., 2008). In Bayesian Learning, a probability model is fitted to a set of data and a summarized result of a probability distribution on the parameters in the model and on the unobserved quantities is produced (Kruschke, 2015). Bayes' theorem utilizes the method of updating the probability density function which represents the uncertainty about the value of a parameter (Hamada et al., 2008). Bayes' theorem may be produced as (Hamada et al., 2008):

$$
p(\theta \mid y)=\frac{f(y \mid \theta) p(\theta)}{m(y)},
$$

where

$$
m(y)=\int f(y \mid \theta) p(\theta) d \theta,
$$

and where $p(\theta \mid y)$ is known as the posterior density, $p(\theta)$ the prior density, $m(y)$ the marginal density of the data and $f(y \mid \theta)$ the sampling density of the data which represents the likelihood function.

\section{RESULT}

The result outlined are ALE, Order Power Spectrum and Bayesian Learning of the measured vibration signal on the torque converter, gearbox and axle. The stochastic part of the vibration is related to the Gearbox bearings and the deterministic part is related to the gears. The deterministic part of the signal tends to mask the bearing signal, hence the need to separate the stochastic part from the deterministic part after the vibration signal has been synchronously resampled to the order domain (Källstöm et al., 2017). The Order Power Spectrum better reveals the orders of the gears and bearings of the gearbox. With Bayesian Learning the extracted features are learned so as to identity a potential failure. In addition, the Bayesian Learning is updated for incoming vibration feature. The like- 
lihood is a measure of the Order Power Spectrum from measured vibration and the prior, which is also an Order Power Spectrum estimate updated with in coming vibration.

\subsection{Torque Converter}

The results outlined below are a Order Power Spectrum estimation and a Bayesian Learning estimate of the measured vibration signal around the torque converter of the $\mathrm{L} 180 \mathrm{H}$ Wheel Loader.

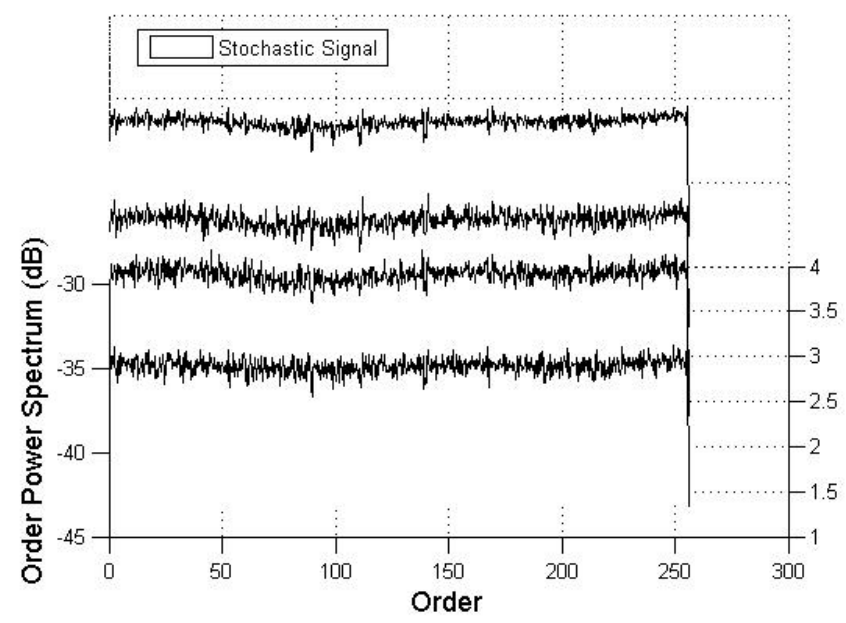

Figure 8. Order Power Spectrum of the Torque Converter Stochastic Signal (Bearings).

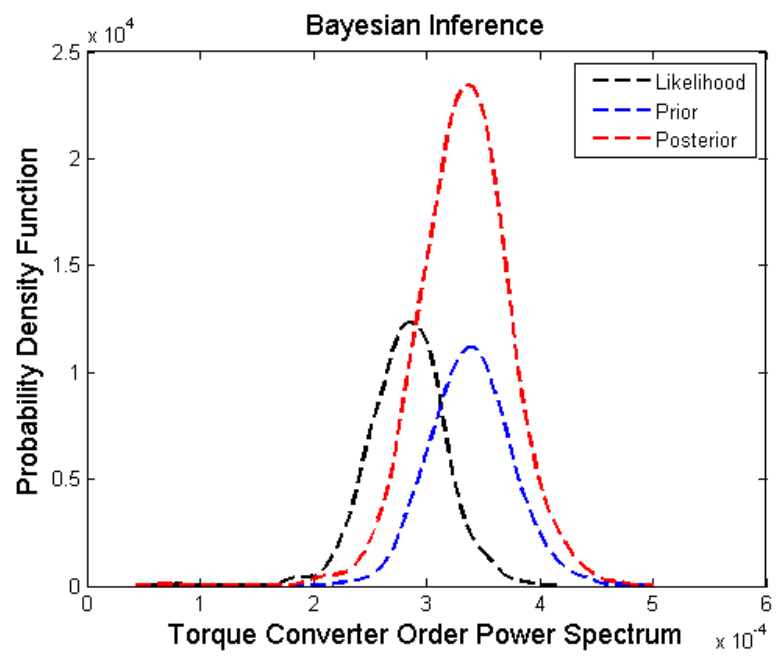

Figure 9. Bayesian Learning of Torque Converter Stochastic Signal.

The orders 29, 27 and 13 and their harmonics correspond to the torque converter's impeller, turbine and stator respectively in Figure 10. In addition, harmonics of the order 29, which correspond to the impeller, are more pronounced around order 87 on the order power spectrum.

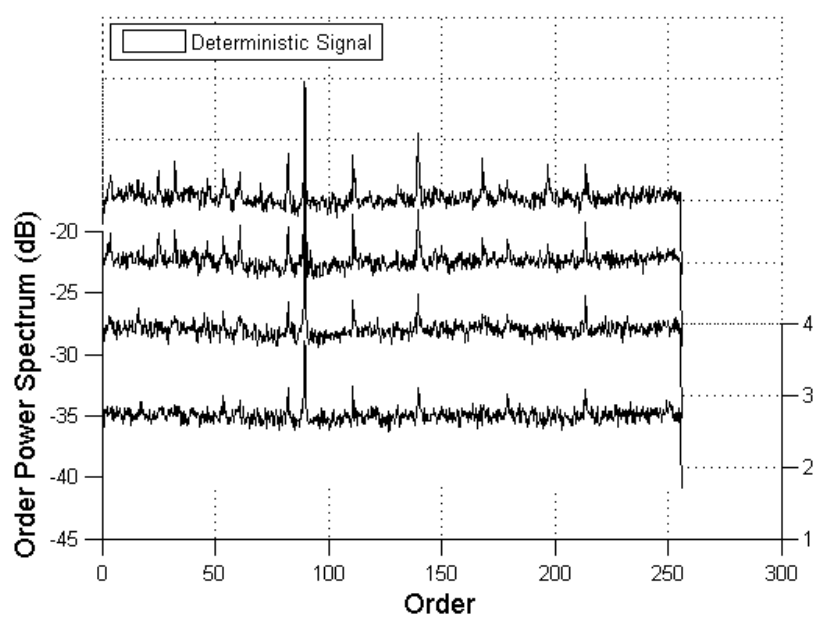

Figure 10. Order Power Spectrum of the Torque Converter Deterministic Signal.

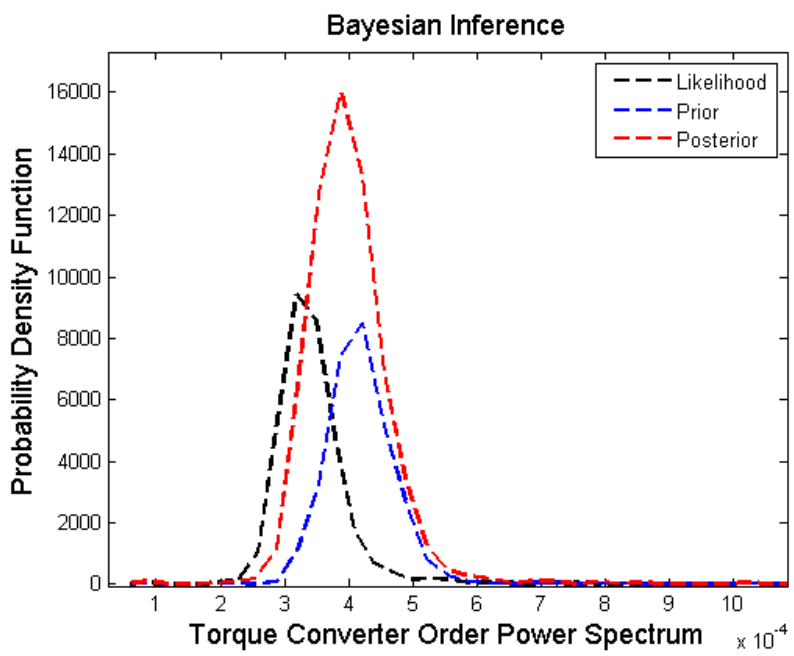

Figure 11. Bayesian Learning of Torque Converter Deterministic Signal.

Monitoring the orders of the torque converter's stochastic and deterministic vibration onboard via Bayesian Learnings is shown in Figures 9 and 11 respectively This may enable early fault detection of transmission gears and bearings.

\subsection{Gearbox}

The stochastic part of the vibration is related to the gearbox bearings and the deterministic part is related to the gears. Information related to the gearbox bearings are revealed in the orders of the Order Power Spectrum of the stochastic part of 
the gearbox vibration as shown in Figure 12.

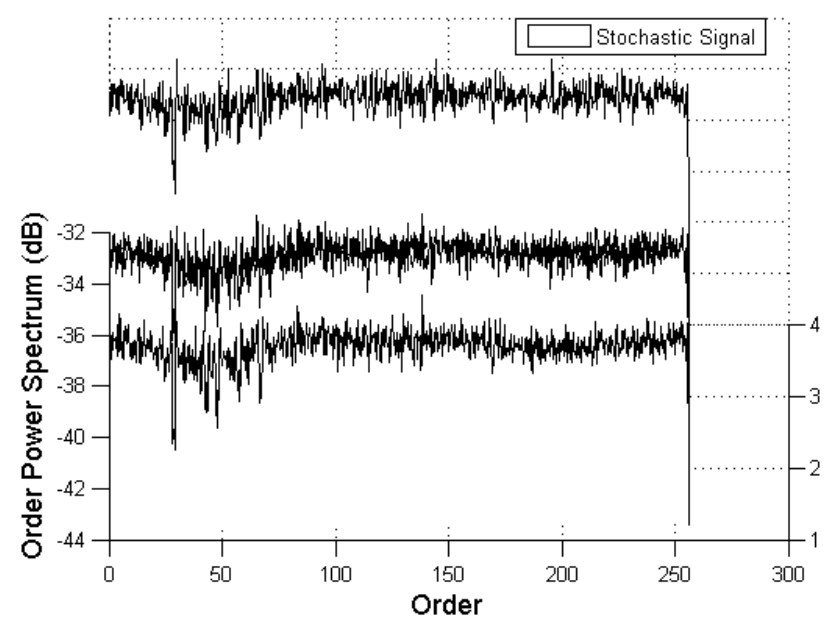

Figure 12. Order Power Spectrum of the Gearbox Stochastic Signal (Bearings).

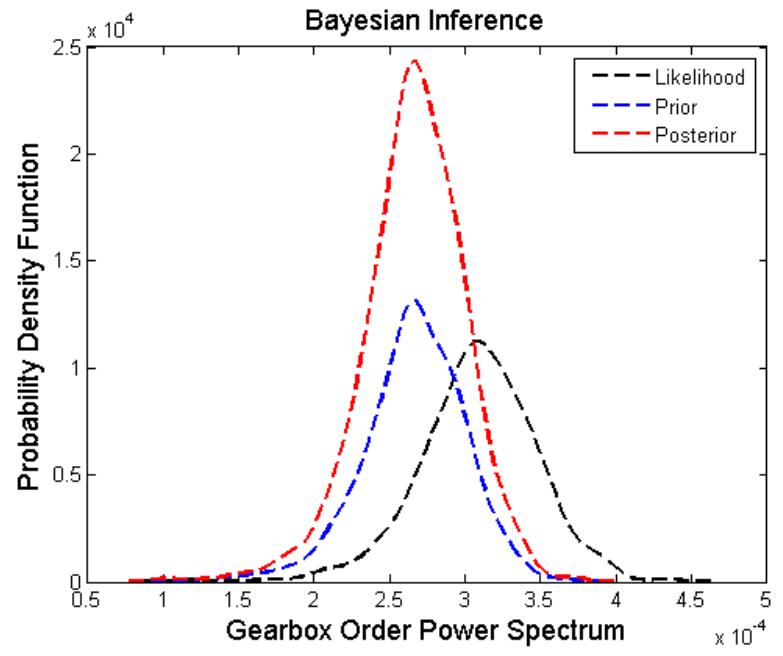

Figure 13. Bayesian Learning of of the Gearbox Stochastic Signal.

The Order Spectrum of the deterministic part provide information related to the engaged gears in the gearbox as shown in Fig. 14. The Order Power Spectrum reveals the orders of the gears and bearings of the gearbox. Monitoring the orders of the stochastic and deterministic vibration onboard via Bayesian Learnings as shown in Figures 13 and 15 respectively, may enable early fault detection of transmission gears and bearings.

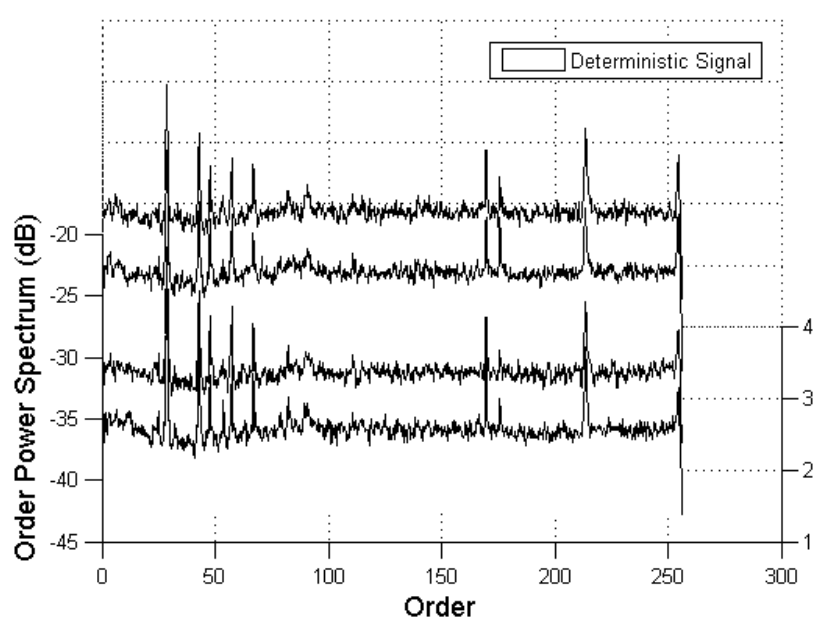

Figure 14. Order Power Spectrum of the Gearbox Deterministic Signal.

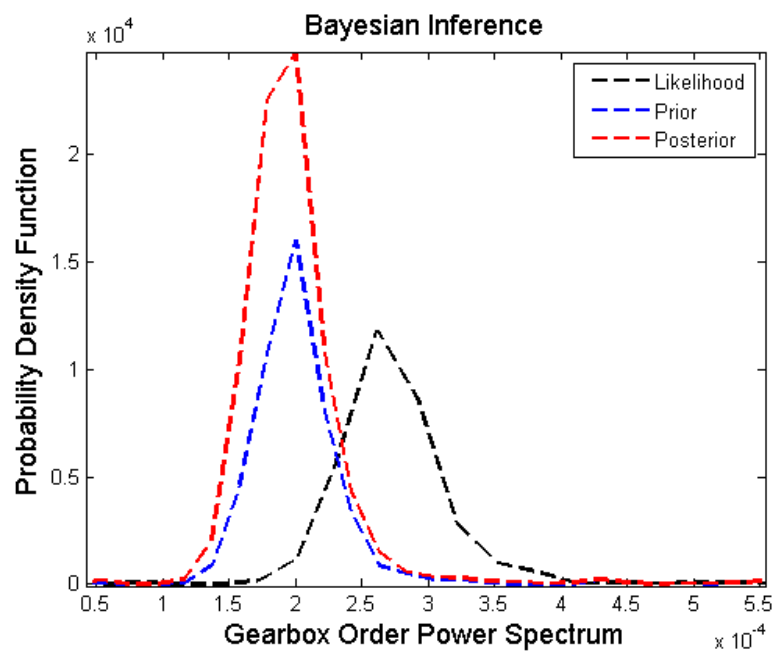

Figure 15. Bayesian Learning of of the Gearbox Deterministic Signal.

\subsection{Axle}

The Order Power Spectrum estimates of the measured vibration signal of the rear axles of the $\mathrm{L} 180 \mathrm{H}$ Wheel Loader are presented.The deterministic signal shows that the orders 9 and its harmonics correspond to the order of the pinion of the axle. The Order Power Spectrum of the rear axle vibration from the accelerometer mounted on the $\mathrm{x}$-direction as in Figure 18 shows that the order of the pinion may be observed around 9, and its harmonics around 27, 45, 54, 81 and 108. 


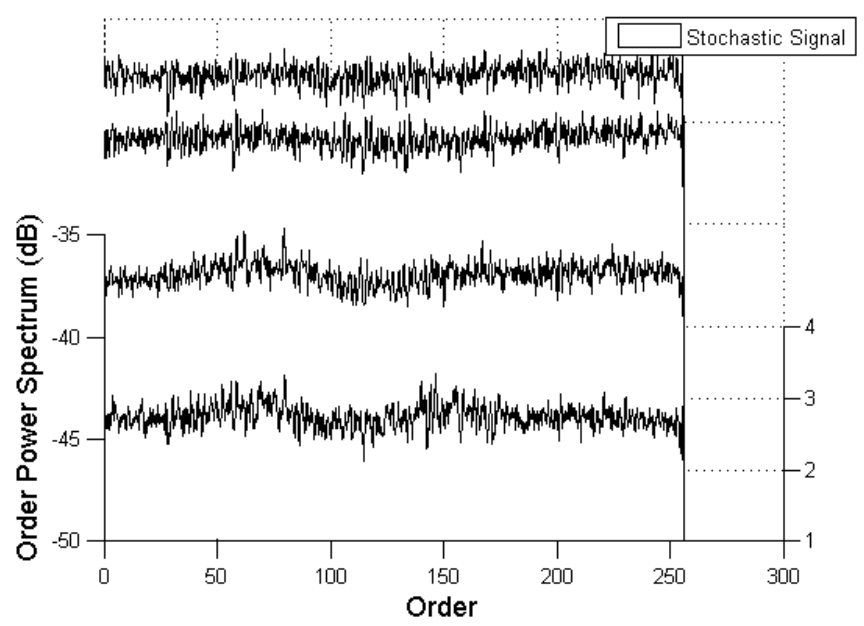

Figure 16. Order Power Spectrum of the Rear Axle Stochastic Signal (Bearings) from the accelerometer mounted on the $\mathrm{X}$ direction

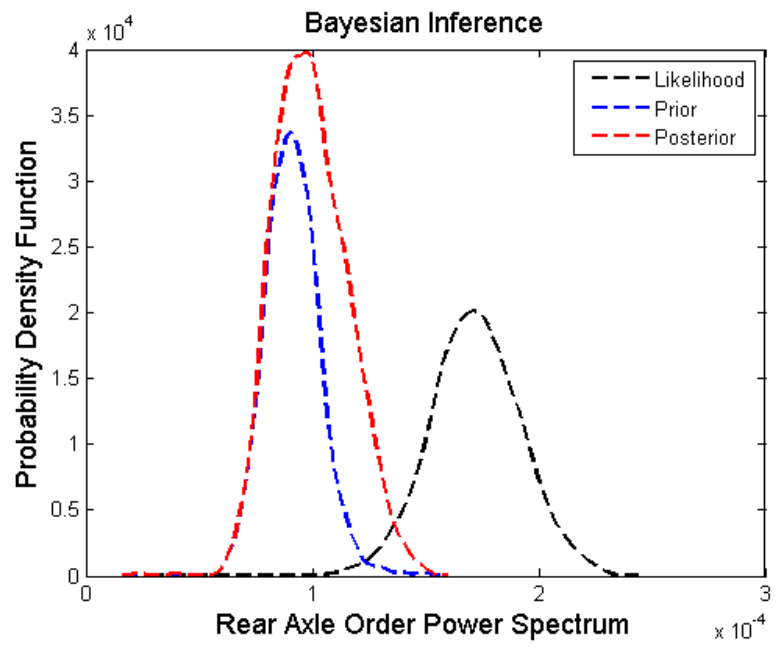

Figure 17. Bayesian Learning of the Rear Axle Stochastic Signal

However, high peaks appear around orders 86, 114, 143, 169 and 254. The stochastic signal of the vibration presented in Fig. 16 is related to the bearings close to the rear axle pinion. Further, the Bayesian Learning estimate of the rear axle stochastic and deterministic signal is presented in Figures 17 and 19 respectively. Thus, the onboard monitoring of the orders concerning the stochastic and deterministic vibration of the axle would enable early deviation detection of the rear axle pinion and bearings close to it.

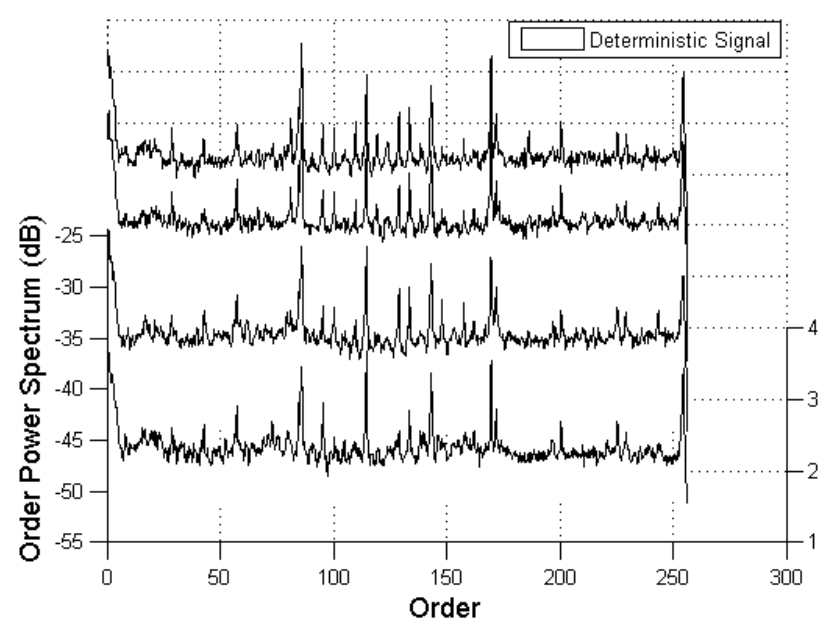

Figure 18. Order Power Spectrum of the Rear Axle Deterministic Signal from the accelerometer mounted on the $\mathrm{x}$ direction.

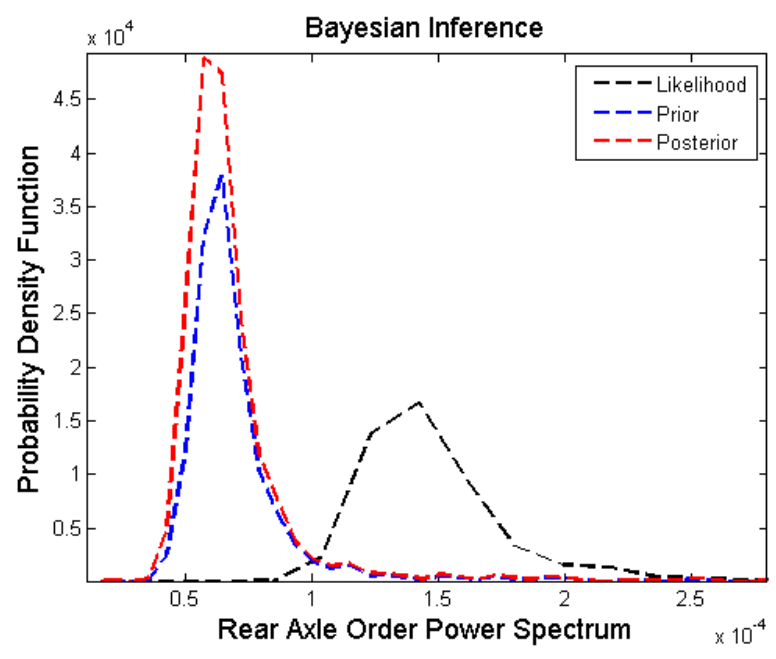

Figure 19. Bayesian Learning of the Rear Axle deterministic Signal

The individual results presented in sections 3.1-3.3 can be combined into a unified framework for vibration-based onboard monitoring of the torque converter, gearbox, bearings and axles as shown in Fig.6. The measured vibration data is a combination of the deterministic signal (gears, turbine, impeller, stator etc) and stochastic signal (bearings) (Källstöm et al., 2017). In this way, a combination of the feature extraction method and Bayesian Learning provides an adaptive learning method for the monitoring of driveline parts given the respective vibration signals and engine rotational speed.

The developed vibration-based monitoring approach developed is generic for automatic transmission and axles of heavy 
duty construction equipment. Thus, it can be extended to other machine variants of heavy duty equipment other than the L180H Wheel Loader. In addition, the developed method is easy to implement. The Volvo CE CoPilot, an andriod tablet computer was utilized.

\section{Discussions AND CONCLUSIONS}

A vibration based diagnosis framework for the monitoring of major components of the driveline of the $\mathrm{L} 180 \mathrm{H}$ Wheel Loader have been presented. The driveline components studied include the gearbox, the torque converter, the bearings and the axles. The developed framework comprises pre-processing of the measured vibration signal by synchronous resampling to the order domain and a further separation of it into deterministic and stochastic parts respectively using an ALE filter. Further analysis is carried out using Order Power Spectrum for feature extraction. In addition, Bayesian Learning is used to adaptively learn the extracted features for deviation detection.

The above results demonstrate that the vibration measured on an actual heavy duty construction equipment contains information related to deviation detection and degradation of critical components of the driveline such as the gearbox, torque converter, bearings and axles.

Furthermore, continuous monitoring of these features onboard gives information about deviations from normal behavior. With such deviation flags, service and maintenance can be scheduled well in advance before a major problem occurs. In addition, the on-board condition monitoring approach, which has been developed, is generic for automatic transmission and axles of heavy duty construction equipment and can be extended to other variants of Volvo CE heavy duty equipment.

In future work, onboard monitoring of the oil may also provide an indication of the gradual degradation of the respective driveline parts. In addition, it would be of interest to consider monitoring of the cardan shaft via vibration sensors onboard as this may enable early fault detection of a cardan shaft. Practically, early fault detection and prediction may save both money and time for the customer and thus increase customer satisfaction. Being able to monitor, preferably online, critical parts and components, such as the torque converter, is a pre-requisite for using result- or availability-based business models such as Industrial Product-Service Systems or Functional Products (Meier, Roy, \& Seliger, 2008; Lindström, Plankina, Parida, \& Karlsson, 2013). These business models are becoming more interesting as additional services, software, knowledge and know-how are added to product offers (Lindström et al., 2013).

\section{REFERENCES}

Abdusslam, S., Gu, F., \& Ball, A. (2009). Bearing fault diagnosis based on vibration signals. In Proceedings of computing and engineering annual researchers' conference (p. 1350-1359).

Andren, L., Håkansson, L., Brandt, A., \& Claesson, I. (1978). Identification of dynamic properties of boring bar vibrations in a continuous boring operation. Mechanical Systems and Signal Processing, 18(4), 869-901.

Bendat, J., \& Piersol, A. (Eds.). (2000). Random data; analysis and measurement procedures, third edition. John Wiley \& Sons.

Brandt, A. (Ed.). (2011). Noise and vibration analysis: Signal analysis and experimental procedures. John Wiley \& Sons.

Brkovic, A., Gajic, D., Gligorijevic, J., Savic-Gajic, I., Georgieva, O., \& S., D. G. (2017). Early fault detection and diagnosis in bearings for more efficient operation of rotating machinery. Energy, 136(1), 63-71.

Fan, X., \& Zuo, M. J. (2006). Gearbox fault detection using hilbert and wavelet packet transform. Mechanical Systems and Signal Processing, 20, 966-982.

Gelman, A., Carlin, J., Stern, H., Dunson, D., Vehtari, A., \& Rubin, D. (Eds.). (2014). Bayesian data analysis, third edition. ISBN 978-1-4398-4095-5, CRC Press.

Giannakis, G. (Ed.). (1999). Cyclostationary signal analysis. Digital Signal Processing Handbook, CRC Press LLC.

Guo, Y., Wu, X., Na, J., \& Fung, R. (2016). Envelope synchronous average scheme for multi-axis gear fault detection. Sound and Vibration, 365, 276-286.

Hamada, M. S., Wilson, A., Reese, C., \& Martz, H. (Eds.). (2008). Bayesian reliability. ISBN 978-0-387-779485, Springer.

Harris, F. (1978). On the use of windows for harmonic analysis with the discrete fourier transform. IEEE, 66(6), 70-73.

Haykin, S. (Ed.). (2014). Adaptive filter theory, (fifth edition). ISBN 978-0-132-67145-3, Pearson Education Limited.

He, D., \& Li, R. (2011). A new vibration signal processing method for fault detection. Mechanical Systems and Signal Processing.

Ho, D., \& Randall, R. (1997). Effects of time delay, order of fir filter and convergence factor on self adaptive noise cancellation. In Proceedings of the fifth international congress on sound and vibration.

Hong, L., \& Dhupia, J. (2014). A time domain approach to gearbox fault based on measured vibration signals. Mechanical Systems and Signal Processing, 333, 21642180.

Huibin, L., Mengxi, N., Chengxia, Z., \& Bo, Y. (2012). Experimental study on the noise identification of the rear driving axle. In Proceedings of international confer- 
ence on intelligent systems design and engineering application (p. 1255-1258).

Immovilli, F., Bellini, A., Rubini, R., \& C., T. (2010). Diagnosis of bearing faults in induction machines by vibration or current signals: A critical comparison. In Ieee transactions on industry application (Vol. 46, p. 13501359).

Junsheng, C., Yu, Y., \& Dejie, Y. (2010). The envelope order spectrum based on generalized demodulation timefrequency analysis and its application to gear fault diagnosis. Mechanical System and Signal Processing, 24(2), 508-521.

Källstöm, E., Lindström, J., Håkansson, L., Karlberg, M., \& Öberg, O. (2017). Identification of vibration properties of wheel loader driveline parts as a base for adequate condition monitoring: Bearings. In 24th international congress on sound and vibration, london, united kingdom, 23-27 july, 2017.

Kruschke, J. K. (Ed.). (2015). Doing bayesian data analysis. ISBN 978-0-12-405888-0, Academic Press.

Li, H., \& Ai, S. (2008). Application of order bi-cepstrum to gearbox fault detection. In Proceedings of the 7th world congress on intelligent control and automation (p. 1781-1785).

Lindström, J., Plankina, K., D.and Nilsson, Parida, H., V.and Ylinenää, \& Karlsson, L. (2013). Functional products: Business model elements. In 5th cirp international conference on industrial product-service systems, bochum, germany (p. 1781-1785).

Meier, H., Roy, R., \& Seliger, G. (2008). Industrial productservice systems. IPS2, CIRP Annals Manufacturing Technology(4), 1-24.

Proakis, J. G., \& Manolakis, D. G. (Eds.). (2006). Digital signal processing: Principles, algorithms, and applications (fourth edition). ISBN:0131873741, PrenticeHall, Inc. Upper Saddle River, NJ, USA.

Ramli, R., Noor, A., \& Samad, S. (2012). A review of adaptive line enhancers for noise cancellation. Australian Journal of Basic and Applied Sciences, 6(6), 337-352.

Randall, R. (Ed.). (n.d.). John Wiley \& Sons, Hoboken, NJ.

Randall, R. (2004a). State of the art in monitoring rotating machinery: Part 1. Sound and Vibration, 14-20.

Randall, R. (2004b). State of the art in monitoring rotating machinery: Part 2. Sound and Vibration, 14-20.

Randall, R., \& Antoni, J. (2011). Rolling element bearing diagnostics-a tutorial. Mechanical System and Signal Processing, 25(2), 485-520.

Randall, R., Sawalhi, N., \& Coats, M. (2011). A comparison of methods for separation of determinstic and random signals. Mechanical System and Signal Processing, 1(1), 11-19.

Santacruz, M., \& Félix, M. (2014). Test point optimization process for a real-time vibration monitoring system on a differential axle fixed rig. In Proceedings of ieee (p. 1255-1258).

Sawalhi, N., \& Randall, R. (2008). Simulating gear and bearing interactions in the presence of faults: Part i. the combined gear bearing dynamic model and the simulation of localised bearing faults. Mechanical Systems and Signal Processing, 22, 1924-1951.

Shao, Y., Liang, J., Gu, F., Chen, Z., \& Ball, A. (2011). Fault prognosis and diagnosis of an automotive rear axle gear using a rbf-bp neural network. 9th International Conference on Damage Assessment of Structures (DAMAS 2011) IOP Publishing, Journal of Physics: Conference Series.

Tuma, J. (Ed.). (2014). Vehicle gearbox noise and vibration: Measurement, signal analysis, signal processing and noise reduction measures. John Wiley \& Sons.

Welch, P. D. (1967). The use of fast fourier transform for the estimation of power spectra: A method based on time averaging over short, modified periodograms. IEEE Transactions on Audio and Electroacoustics(6), $70-73$.

Widrow, B., \& Stearns, S. D. (Eds.). (1985). Adaptive signal processing. ISBN 0-13-004029-0, Prentice-Hall International (UK).

\section{BIOGRAPHIES}

Elisabeth Källström received the M.Sc. degree in Electrical Engineering with emphasis in Signal Processing from Blekinge Institute of Technology, Karlskrona, Sweden, in 2012. She also has a Licentiate degree from Luleå University of Technology, Luleå, Sweden. She is currently pursuing the $\mathrm{PhD}$ degree in the division of Product and Production Development at Luleå University of Technology, Luleå, Sweden. Her research interest include, on-board condition monitoring of driveline parts, base engine and engine aftertreatment systems, data mining of big data, engineering vibrations and diagnostics. She is a member of the International Journal of Acoustics and Vibration (IJAV) where she is also an associate editor. She is currently employed at Volvo CE as a Diagnostic Engineer where she works with onboard diagnostics.

John Lindström is a professor, received his $\mathrm{PhD}$ in information systems science at Luleå University of Technology, Sweden. He manages a Research and Development centre, ProcessIT Innovations, at Luleå University of Technology and his research interests include development processes, availability matters on system and organizational level, as well as modeling and simulation applied in industrial development processes. One of his main research interests lies in the area of product development for function provision i.e. functional product development. He has published research papers at international journals and conference proceedings. Prior to joining academy, he worked for 15 years in different industries in both management and specialist positions with product, service, process, and business development. 
Lars Håkansson received the M.Sc. degree in Electrical Engineering from Lund University of Technology, Lund, Sweden, and the Ph.D. degree, in Mechanical Engineering from Lund University of Technology, Lund, Sweden, in 1989 and 1999, respectively. He joined Blekinge Institute of Technology (BTH) and was appointed Senior Lecturer in Electrical Engineering and continued to expand his research within the area of noise and vibration control. In 2005 he was appointed associate professor and received the responsibility, as principal researcher and advisor, for the active control group at the Department of Signal Processing, BTH. Currently, he is professor in mechanical engineering at department of Mechanical Engineering, at Linnaeus University (LNU), Sweden. His current research interests are in Signal Analysis, Signal Processing, Adaptive Signal Processing, Active Noise and Vibration Control, Automatic Control, Remotely Controlled Laboratories, Analytical and Experimental Modeling of Mechanical and Acoustic Systems. He has a keen interest on developing new technology and his research is generally in collaboration with industry, which led to several patents. Lars Håkansson is a member of the Scandinavian vibration association (SVIB) and a member of the Editorial Board of the Journal of Advances in Acoustics and Vibration.
Magnus Karlberg is a Professor in Computer Aided Design (CAD) at LuleåUniversity of Technology, head of division of Product- and Production Development. Karlberg was the director of VINNOVA Excellence centre the Faste Laboratory where research was conducted on Functional Product Innovation between 2007 and 2016. His research interests include functional product innovation, simulation driven design, product development, rotor dynamics, nonlinear dynamics and availability.

Janet (Jing) Lin is currently working as an associate Professor at Division of Operation and Maintenance Engineering, LuleåUniversity of Technology (LTU), Luleå, Sweden. She is research coordinator of joint CSSC (China)-LTU Research lab for maritime transport system, and is also coordinating the development of the research program for the proposed joint CRRC (China)-LTU research center for the rolling stocks. she obtained her $\mathrm{PhD}$ in Management at Nanjing University of Science \& Technology, on April 2008. She worked as a Senior Asset Management Consultant from March 2008 to January 2011 in SKF Ltd., Co. Dr. Lins research interests are mainly on Operation and Maintenance Engineering. 